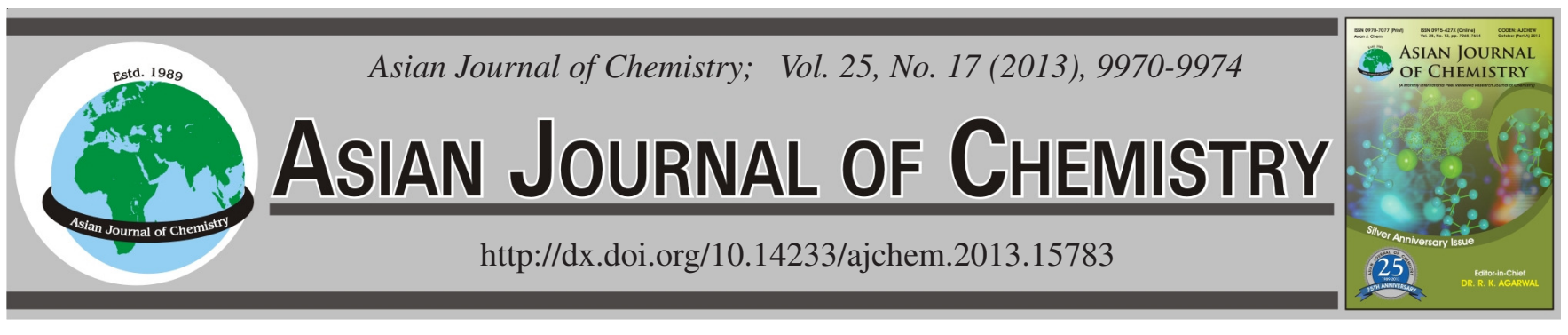

\title{
A Supramolecular Trinuclear Nickel(II) Complex with Asymmetric Salamo-type Ligand: Synthesis and Crystal Structure
}

\author{
W.-K. Dong*, J.-L. Meng, X.-Y. Zhang, M.-M. ZhaO, G. Li and X.-Y. Dong
}

School of Chemical and Biological Engineering, Lanzhou Jiaotong University, Lanzhou 730070, P.R. China

*Corresponding author: E-mail: dongwk@126.com

A supramolecular trinuclear $\mathrm{Ni}(\mathrm{II})$ complex, namely $\left\{[\mathrm{NiL}(\mathrm{EtOH})(\mu-\mathrm{OAc})]_{2} \mathrm{Ni}\right\} \cdot \mathrm{EtOH}$, has been synthesized through the complexation of nickel(II) acetate tetrahydrate with 5-methoxy-4'-bromo-2,2'-[ethylenedioxybis(nitrilomethylidyne)]diphenol ( $\mathrm{H}_{2} \mathrm{~L}$ ). The $\mathrm{Ni}$ (II) complex comprises three $\mathrm{Ni}(\mathrm{II})$ atoms, two deprotonated $\mathrm{L}^{2-}$ units, two acetate aions, two coordinated and one non-coordinated ethanol molecules. In the crystal structure, the terminal $\mathrm{Ni}(\mathrm{II})\left(\mathrm{Ni} 2\right.$ or $\mathrm{Ni}^{\# 1}$ ) atom is located in the cis- $\mathrm{N}_{2} \mathrm{O}_{2}$ coordination cavity of the $\mathrm{L}^{2-}$ units and coordinated to an oxygen $(\mathrm{O} 7)$ atom from the $\mu$-acetato anion and an oxygen $(\mathrm{O} 8)$ atom from the coordinated ethanol molecule in the axial positions. Meanwhile, the central Ni(II) (Ni1) atom is completed by quadruple $\mu$-phenoxo oxygen $\left(\mathrm{O} 3, \mathrm{O} 4, \mathrm{O}^{\# 1}\right.$ and $\left.\mathrm{O} 4^{\# 1}\right)$ atoms from two $\mathrm{L}^{2-}$ units and double $\mu$-acetato oxygen $\left(\mathrm{O} 6\right.$ and $\left.\mathrm{O}^{\# 1}\right)$ atoms. All the $\mathrm{Ni}(\mathrm{II})$ atoms are hexa-coordinated, showing slightly distorted octahedral coordination arrangements. The $\mathrm{Ni}(\mathrm{II})$ complex is linked to form an infinite 2D layer supramolecular structure through intermolecular $\mathrm{O}-\mathrm{H} \cdots \mathrm{O}, \mathrm{C}-\mathrm{H} \cdots \mathrm{O}$ and $\mathrm{C}-\mathrm{H} \cdots \pi$ hydrogen bond interactions.

Key Words: Asymmetric Salamo-type ligand, Ni(II) complex, Synthesis, Crystal structure.

\section{INTRODUCTION}

The syntheses and researches of metal-organic complexes with supramolecular architectures are now ubiquitous ${ }^{1-3}$. The development of novel metal-organic complexes can provide new topologies for functional materials, in which pore size, coordination forms and functionality are all important variables $^{4-6}$. These complexes can be used to obtain non-linear optical materials ${ }^{7-9}$, models of biological systems ${ }^{10,11}$, interesting magnetic properties ${ }^{12-14}$ and building blocks for cyclic supramolecular structures ${ }^{15}$. Although some advances has been made in the studies of Salen-Ni(II) complexes ${ }^{16-18}$, it still seems there could be new and specific applications for such a unique group of compounds. To change the structures or improve the functions of the resulted complexes, chemical modifications of the elemental Salen-type ligand are effective and inevitable. In particular, replacement of some atoms of the ligand with other elements often changes its properties drastically ${ }^{19,20}$. Herein, in continuation to our previous studies ${ }^{21}$, we report the synthesis and crystal structure of a trinuclear $\mathrm{Ni}$ (II) complex with the new asymmetric ligand 5-methoxy-4'-bromo-2,2'-[ethylenedioxybis(nitrilomethylidyne)]diphenol $\left(\mathrm{H}_{2} \mathrm{~L}\right)$.

\section{EXPERIMENTAL}

2-Hydroxy-4-methoxybenzaldehyde $(\geq 99 \%)$ and 2hydroxy-5-bromobenzaldehyde $(\geq 99 \%)$ were purchased from
Alfa Aesar and used without further purification. The other reagents and solvents were analytical grade from Tianjin Chemical Reagent Factory. Elemental analysis for Ni was detected by an IRIS ER/S.WP-1 ICP atomic emission spectrometer. $\mathrm{C}, \mathrm{H}$ and $\mathrm{N}$ analyses were obtained using a $\mathrm{GmbH}$ VarioEL V3.00 automatic elemental analysis instrument. $\mathrm{X}$-ray single crystal structure determination was carried out on a Bruker Smart 1000 CCD diffractometer. Melting points were measured by the use of a microscopic melting point apparatus made in Beijing Taike Instrument Limited Company and the thermometer was uncorrected.

Synthesis of ligand $\mathbf{H}_{2} \mathrm{~L}$ : The major reaction steps involved in the synthesis of $\mathrm{H}_{2} \mathrm{~L}$ are given in Scheme-I.

$\mathrm{H}_{2} \mathrm{~L}$ was synthesized according to an analogous method reported earlier ${ }^{21 \mathrm{~d}}$. Yield 73.8 \%. m.p. 385-387 K. Anal. calcd. for $\mathrm{C}_{17} \mathrm{H}_{17} \mathrm{~N}_{2} \mathrm{O}_{5} \mathrm{Br}(\%)$ : C, 49.89; H, 4.19; N, 6.85. Found: C, 49.75; H, 4.32; N, 6.99 .

Synthesis of $\mathrm{Ni}(\mathrm{II})$ complex: A solution of $\mathrm{Ni}(\mathrm{OAc})_{2} \cdot 4 \mathrm{H}_{2} \mathrm{O}$ (3.73 mg, $0.015 \mathrm{mmol}$ ) in ethanol ( $2 \mathrm{~mL})$ was added dropwise to a solution of $\mathrm{H}_{2} \mathrm{~L}(4.09 \mathrm{mg}, 0.01 \mathrm{mmol})$ in acetonitrile (2 $\mathrm{mL}$ ) at room temperature. The colour of the mixing solution turned to green immediately, then stirred for $1 \mathrm{~h}$ at room temperature. The mixture was filtered off and the filtrate was allowed to stand at room temperature for about one week, the solvent was partially evaporated and obtained green block-like single 


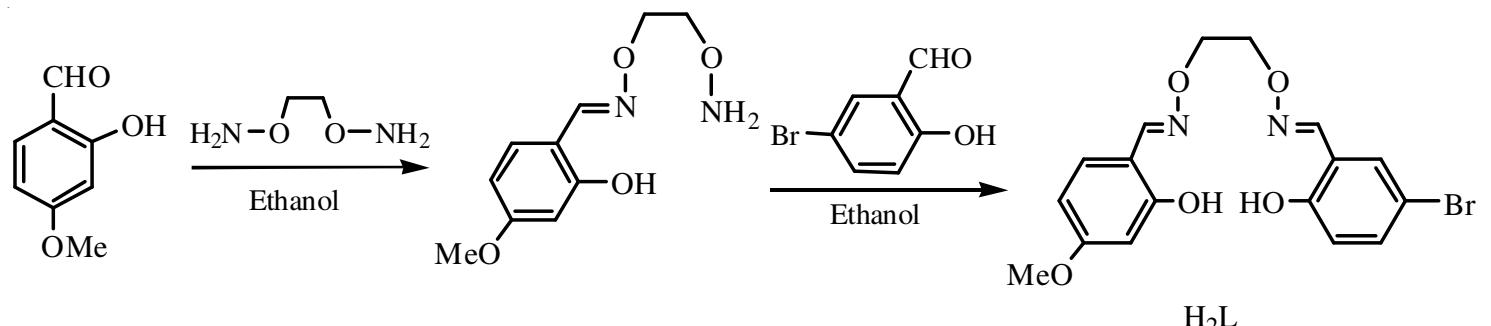

Scheme-I: Synthetic route to the asymmetrical salamo-type ligand $\mathrm{H}_{2} \mathrm{~L}$

crystals suitable for $\mathrm{X}$-ray crystallographic analysis. Anal. calcd. for $\mathrm{C}_{46} \mathrm{H}_{60} \mathrm{~N}_{4} \mathrm{O}_{18} \mathrm{Br}_{2} \mathrm{Ni}_{3}(\%)$ : C, 42.73; H, 4.68; N, 4.33; $\mathrm{Ni}, 13.62$. Found: C, 42.88; H, 4.85; N, 4.12; Ni, 13.58 .

$\mathrm{X}$-Ray structure determination: The crystal data and structure refinement for the $\mathrm{Ni}$ (II) complex are given in Table1 . The single crystal of the $\mathrm{Ni}(\mathrm{II})$ complex with the approximate dimensions of $0.14 \times 0.09 \times 0.08 \mathrm{~mm}$ was placed on a Bruker Smart 1000 CCD area detector. The reflections were collected using a graphite monochromated $\mathrm{MoK}_{\alpha}$ radition $(\lambda=0.71073 \AA)$ at $298(2) \mathrm{K}$. The structure was solved by using the program SHELXL-97 and Fourier difference techniques and refined by the full-matrix least-squares method on $\mathrm{F}^{2}$. The non-hydrogen atoms were refined anisotropically. All hydrogen atoms were added theoretically.

\begin{tabular}{ll}
\multicolumn{2}{c}{ TABLE-1 } \\
\multicolumn{1}{c}{$\begin{array}{l}\text { CRYSTAL DATA AND STRUCTURE REFINEMENT } \\
\text { FOR THE Ni(II) COMPLEX }\end{array}$} \\
\hline Empirical formula & $\mathrm{C}_{46} \mathrm{H}_{60} \mathrm{~N}_{4} \mathrm{O}_{18} \mathrm{Br}_{2} \mathrm{Ni}_{3}$ \\
Formula weight & 1292.93 \\
Temperature $(\mathrm{K})$ & $298(2)$ \\
Wavelength $(\AA)$ & 0.71073 \\
Crystal system & Triclinic \\
Space group & $\mathrm{P}-1$ \\
Cell dimensions, $(\AA$, deg) & $\mathrm{a}=9.2829(8), \mathrm{b}=11.0400(9), \mathrm{c}$ \\
& $=14.220(1)$, \\
& $\alpha=69.940(1), \beta=84.361(2)$, \\
Volume $\left(\AA^{3}\right)$ & $\gamma=77.960(1)$ \\
$Z$ & $1338.2(2)$ \\
Density (calculated) $\left(\mathrm{mg} / \mathrm{m}^{3}\right)$ & 1 \\
Absorption coefficient $\left(\mathrm{mm}^{-1}\right)$ & 1.604 \\
$\mathrm{~F}_{\text {(o00) }}$ & 2.611 \\
Index ranges & 662 \\
& $-11 \leq \mathrm{h} \leq 10,-13 \leq \mathrm{k} \leq 12,-14 \leq 1$ \\
Reflections collected & $\leq 16$ \\
Independent reflections & $6329 / 4537[\mathrm{R}(\mathrm{int})=0.0520]$ \\
Data/restraints/parameters & 1313 \\
Goodness of fit indicator & $4537 / 0 / 364$ \\
$\mathrm{R}[\mathrm{I}>2 \sigma(\mathrm{I})]$ & 1.056 \\
Largest diff. peak and hole $\left(\mathrm{e} \AA^{-3}\right)$ & 1.201 and -0.947 \\
\hline
\end{tabular}

\section{RESULTS AND DISCUSSION}

Crystal structure of the Ni(II) complex: ORTEP representation of the Ni(II) complex is shown in Fig. 1. Selected bond lengths and angles are listed in Table- 2 .

X-ray crystallographic analysis reveals that the $\mathrm{Ni}$ (II) complex is a neutral homotrinuclear entity with crystallographic inversion symmetry and crystallizes in the triclinic system, space group P-1 with a linear trinuclear array of three
$\mathrm{Ni}(\mathrm{II})$ ions coupled by both doubly $\mu$-phenoxo oxygen atoms of $\mathrm{L}^{2-}$ units and simultaneously two acetate anions in the synsyn bridging mode, as well as one non-coordinated ethanol molecule. As shown in Fig. 1, all the hexa-coordinated Ni(II) ions of the $\mathrm{Ni}$ (II) complex have a slightly distorted octahedral coordinated polyhedron. The two terminal Ni(II) (Ni2 and $\mathrm{Ni} 2^{\# 1}$ ) atoms are both located in the $\mathrm{N}_{2} \mathrm{O}_{2}$ coordination cavity of the $\mathrm{L}^{2-}$ units and coordinated to oxygen $(\mathrm{O} 7)$ atom from the $\mu$-acetato anion and oxygen (O8) atom from the coordinated ethanol molecule in the axial positions. Meanwhile, the coordination sphere of the central $\mathrm{Ni}(\mathrm{II})$ atom (Ni1) is completed by quadruple $\mu$-phenoxo oxygen $\left(\mathrm{O} 3, \mathrm{O} 4, \mathrm{O}^{\# 1}\right.$ and $\left.\mathrm{O}^{\# 1}\right)$ atoms from two $\mathrm{L}^{2-}$ units and double $\mu$-acetato oxygen $\left(\mathrm{O} 6\right.$ and $\mathrm{O6}^{\# 1}$ ) atoms, which adopt a familiar $\mu-\mathrm{O}-\mathrm{C}-\mathrm{O}$ fashion. All the six oxygen atoms coordinated to Nil atom constitute an octahedral arrangement: one acetate anion serves as bridging group for $\mathrm{Ni} 2$ and $\mathrm{Ni} 1$ and the other coordinates to $\mathrm{Ni}_{2}^{\# 1}$ and $\mathrm{Ni1}$, in both cases via $\mathrm{Ni}-\mathrm{O}-\mathrm{C}-\mathrm{O}-\mathrm{Ni}$ bridges. In addition, the coordination equatorial plane of O3-O4-N2-N1 parallel to another equatorial plane of $\mathrm{O} 3^{\# 1}-\mathrm{O} 4^{\# 1}-\mathrm{N} 2^{\# 1}-\mathrm{N} 1^{\# 1}$.

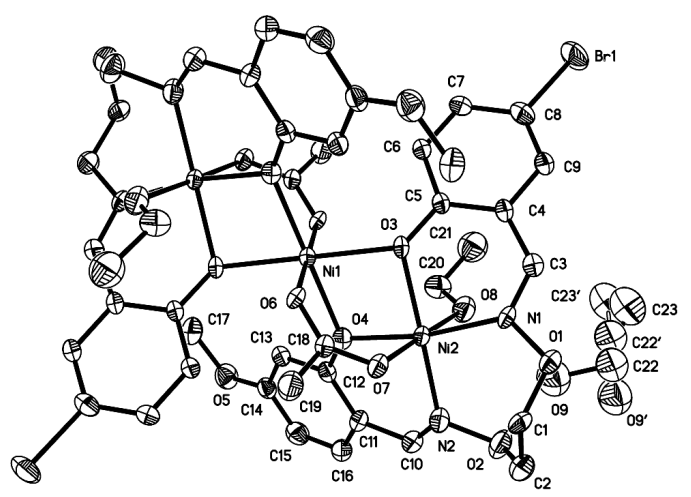

Fig. 1. ORTEP-style drawing of the Ni(II) complex

There is an inversion center through central Nil ion and the distance of Ni1-O3 [2.131(7) $\AA$ ] is shorter than that of Ni1-O6 (2.047(8) A), indicating a weaker steric effect. Furthermore, the terminal $\mathrm{Ni}(\mathrm{II})\left(\mathrm{Ni} 2\right.$ or $\mathrm{Ni}_{2}^{\# 1}$ ) atom is $0.114(3)$ $\AA$ out of the $\mathrm{N}_{2} \mathrm{O}_{2}$ equatorial plane, but the central $\mathrm{Ni}$ (II) (Ni1) atom lies in the corresponding $\mathrm{O}_{2} \mathrm{O}_{2}$ equatorial plane. The Ni2$\mathrm{N} 1$ bond [2.084(10) $\AA$ ] is slightly longer than Ni2-N2 bond [2.049(11) $\AA$ ], which is attributed to the ethanol molecule coordinating to the terminal $\mathrm{Ni}(\mathrm{II})\left(\mathrm{Ni} 2\right.$ and $\left.\mathrm{Ni}^{\# 1}\right)$ ions, resulting in the larger steric hindrance. The Ni1-Ni2 distance $[3.093(3) \AA]$ is significantly longer than all the Ni-O and Ni-N bonds (2.016-2.220 ̊), indicating weak inter-metal interaction, similar to that previously reported ${ }^{22}$ for a Salen-type cluster, $\left\{\left[\mathrm{Ni}(\mathrm{Salpr}) \mathrm{NC}_{5} \mathrm{H}_{5}\right]_{2}(\mu \mathrm{OAc})_{2} \mathrm{Ni}\right\}$. 
TABLE-2

SELECTED BOND LENGTHS $(\AA)$ AND ANGLES $\left({ }^{\circ}\right)$ FOR THE COMPLEX

\begin{tabular}{|c|c|c|c|c|c|}
\hline Bond & Lengths & Bond & Lengths & Bond & Lengths \\
\hline Ni1-O6 ${ }^{\# 1}$ & $2.047(8)$ & Ni1-O4 & $2.139(8)$ & Ni2-N2 & $2.049(11)$ \\
\hline Ni1-O6 & $2.047(8)$ & $\mathrm{Ni1}-\mathrm{O} 4^{\# 1}$ & $2.139(8)$ & Ni2-O7 & $2.076(8)$ \\
\hline $\mathrm{Ni1}-\mathrm{O}^{\# 1}$ & $2.131(7)$ & Ni2-O4 & $2.016(8)$ & Ni2-N1 & $2.084(10)$ \\
\hline Ni1-O3 & $2.131(7)$ & $\mathrm{Ni2}-\mathrm{O} 3$ & $2.035(7)$ & $\mathrm{Ni2}-\mathrm{O} 8$ & $2.220(10)$ \\
\hline Bond & Angles & Bond & Angles & Bond & Angles \\
\hline $\mathrm{O}^{\# 1}$-Ni1-O6 & $180.0(4)$ & O4-Ni2-O3 & $83.8(3)$ & N1-Ni2-O8 & $85.4(4)$ \\
\hline $\mathrm{O}^{\# 1}-\mathrm{Ni1}-\mathrm{O} 3^{\# 1}$ & $88.2(3)$ & O4-Ni2-N2 & $90.1(4)$ & C3-N1-Ni2 & $122.3(8)$ \\
\hline O6-Ni1-O3 ${ }^{\# 1}$ & $91.8(3)$ & O3-Ni2-N2 & $168.8(4)$ & O1-N1-Ni2 & $126.3(7)$ \\
\hline $\mathrm{O6}^{\# 1}$-Ni1-O3 & $91.8(3)$ & O4-Ni2-O7 & $87.9(3)$ & C10-N2-Ni2 & $123.6(8)$ \\
\hline O6-Ni1-O3 & $88.2(3)$ & O3-Ni2-O7 & $94.3(3)$ & $\mathrm{O} 2-\mathrm{N} 2-\mathrm{Ni} 2$ & $120.4(8)$ \\
\hline $\mathrm{O}^{\# 1}-\mathrm{Ni1}-\mathrm{O} 3$ & $180.0(1)$ & N2-Ni2-O7 & $94.8(4)$ & $\mathrm{C} 5-\mathrm{O} 3-\mathrm{Ni} 2$ & $122.4(6)$ \\
\hline $\mathrm{O6}^{\# 1}-\mathrm{Ni1}-\mathrm{O} 4$ & $90.9(3)$ & O4-Ni2-N1 & $170.3(3)$ & C5-O3-Ni1 & $133.1(7)$ \\
\hline O6-Ni1-O4 & 89.1(3) & O3-Ni2-N1 & $86.8(3)$ & Ni2-O3-Ni1 & $95.9(3)$ \\
\hline $\mathrm{O}^{\# 1}-\mathrm{Ni1}-\mathrm{O} 4$ & $101.4(3)$ & N2-Ni2-N1 & $98.8(4)$ & $\mathrm{C} 12-\mathrm{O} 4-\mathrm{Ni} 2$ & $128.2(7)$ \\
\hline O3-Ni1-O4 & $78.6(3)$ & O7-Ni2-N1 & 95.2(4) & C12-O4-Ni1 & $134.2(7)$ \\
\hline $\mathrm{O}^{\# 1}-\mathrm{Ni1}-\mathrm{O} 4^{\# 1}$ & $89.1(3)$ & $\mathrm{O} 4-\mathrm{Ni} 2-\mathrm{O} 8$ & $91.6(3)$ & Ni2-O4-Ni1 & $96.2(3)$ \\
\hline O6-Ni1-O4 ${ }^{\# 1}$ & $90.9(3)$ & O3-Ni2-O8 & $86.9(3)$ & C18-O6-Ni1 & $129.5(8)$ \\
\hline $\mathrm{O}^{\# 1}-\mathrm{Ni1}-\mathrm{O} 4^{\# 1}$ & $78.6(3)$ & N2-Ni2-O8 & $83.9(4)$ & $\mathrm{C} 18-\mathrm{O} 7-\mathrm{Ni} 2$ & $126.2(8)$ \\
\hline $\mathrm{O} 3-\mathrm{Ni1}-\mathrm{O} 4^{\# 1}$ & $101.4(3)$ & O7-Ni2-O8 & $178.6(3)$ & $\mathrm{C} 20-\mathrm{O} 8-\mathrm{Ni} 2$ & $128.5(8)$ \\
\hline O4-Ni1-O4 ${ }^{\# 1}$ & $180.0(1)$ & - & - & - & - \\
\hline
\end{tabular}

Symmetry transformations used to generate equivalent atoms: ${ }^{\# 1}-\mathrm{x}+1,-\mathrm{y}+1,-\mathrm{z}+1$

TABLE-3

THE DATA FOR HYDROGEN-BONDING INTERACTIONS $\left(\AA{ }^{\circ}{ }^{\circ}\right)$

\begin{tabular}{|c|c|c|c|c|c|}
\hline $\mathrm{D}-\mathrm{H} \cdots \mathrm{A}$ & $\mathrm{d}(\mathrm{D}-\mathrm{H})$ & $\mathrm{d}(\mathrm{H} \cdots \mathrm{A})$ & $\mathrm{d}(\mathrm{D} \cdots \mathrm{A})$ & $\angle \mathrm{D}-\mathrm{H} \cdots \mathrm{A}$ & Symmetry code \\
\hline 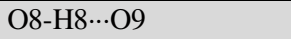 & 0.82 & 2.00 & $2.82(2)$ & 176 & $\mathrm{x}, \mathrm{y}, \mathrm{z}$ \\
\hline $\mathrm{O} 9-\mathrm{H} 9 \cdots \mathrm{O} 2$ & 0.82 & 2.07 & $2.89(2)$ & 172 & $\mathrm{x}, \mathrm{y}, \mathrm{z}$ \\
\hline $\mathrm{C} 15-\mathrm{H} 15 \cdots \mathrm{O} 9$ & 0.93 & 2.59 & $3.47(3)$ & 157 & $-x, 2-y, 1-z$ \\
\hline $\mathrm{C} 1-\mathrm{H} 1 \mathrm{~A} \cdots \mathrm{O} 7$ & 0.97 & 2.30 & $3.21(2)$ & 157 & $\mathrm{x}, \mathrm{y}, \mathrm{z}$ \\
\hline $\mathrm{C} 13-\mathrm{H} 13 \cdots \mathrm{O} 3$ & 0.93 & 2.59 & $3.34(2)$ & 137 & $1-x, 1-y, 1-z$ \\
\hline C20-H20A $\cdots$ O6 & 0.97 & 2.46 & $3.42(2)$ & 173 & $1-x, 1-y, 1-z$ \\
\hline C2-H2B $\cdots \pi_{\text {centroid(C11-C16) }}$ & 0.97 & 2.72 & $3.64(2)$ & 159 & $1-x, 2-y, 1-z$ \\
\hline
\end{tabular}

Intermolecular interactions of the $\mathrm{Ni}(\mathrm{II})$ complex: The $\mathrm{Ni}$ (II) complex contains one non-coordinating ethanol molecule and complicated hydrogen bonding interactions, such as intramolecular, intermolecular and $\mathrm{C}-\mathrm{H} \cdots \mathrm{p}$ hydrogen bonds and hydrogen bond data are summarized in Table- 3 .

The Ni(II) complex stabilized by three pairs of weak

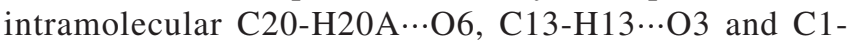
$\mathrm{H} 1 \mathrm{~A} \cdots \mathrm{O} 7$ hydrogen-bonding interactions (Fig. 2). Furthermore, each oxygen $(\mathrm{O} 9)$ atom of the non-coordinating ethanol molecule is hydrogen-bonded to the - $\mathrm{O} 8 \mathrm{H} 8$ group of the coordinating ethanol molecule and the $-\mathrm{C} 15 \mathrm{H} 15$ group of the benzene ring, respectively, while its -O9H9 group is hydrogen- bonded

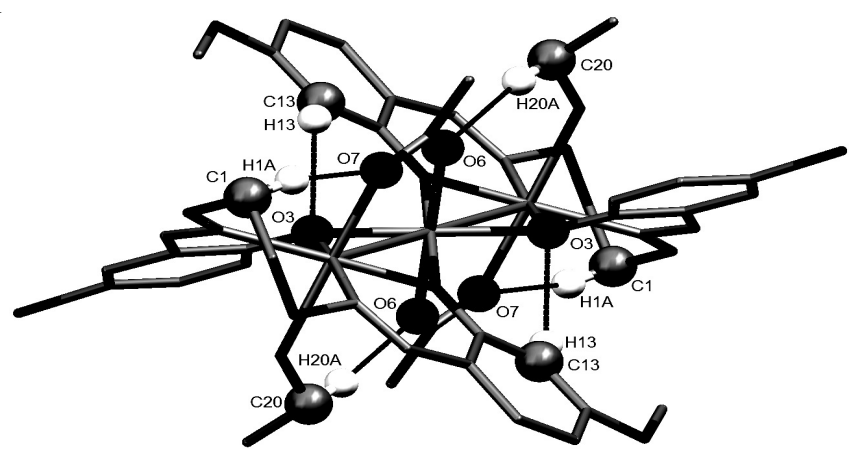

Fig. 2. View of the intramolecular hydrogen-bonding interactions of the complex

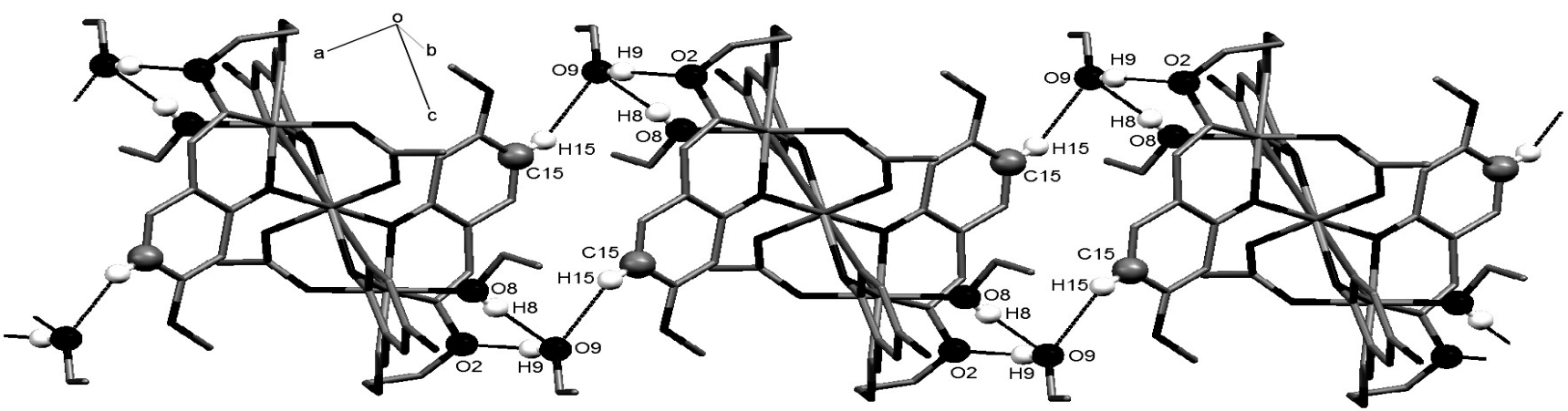

Fig. 3. View of the 1D chain motif of the complex units along the [110] crystallographic axis (hydrogen atoms, except those forming hydrogen bonds, are omitted for clarity) 


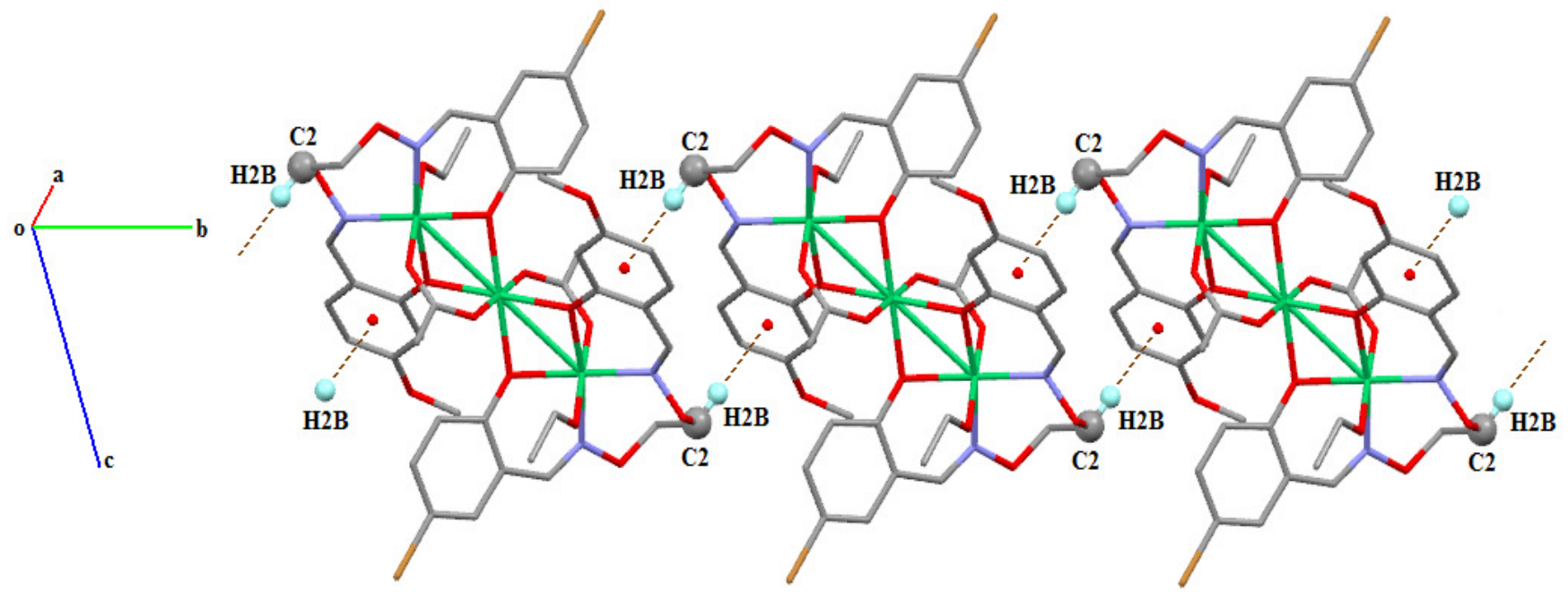

Fig. 4. (color online). View of the 1D chain motif of the complex units along the $b$ axis (hydrogen atoms, except those forming hydrogen bonds, are omitted for clarity).

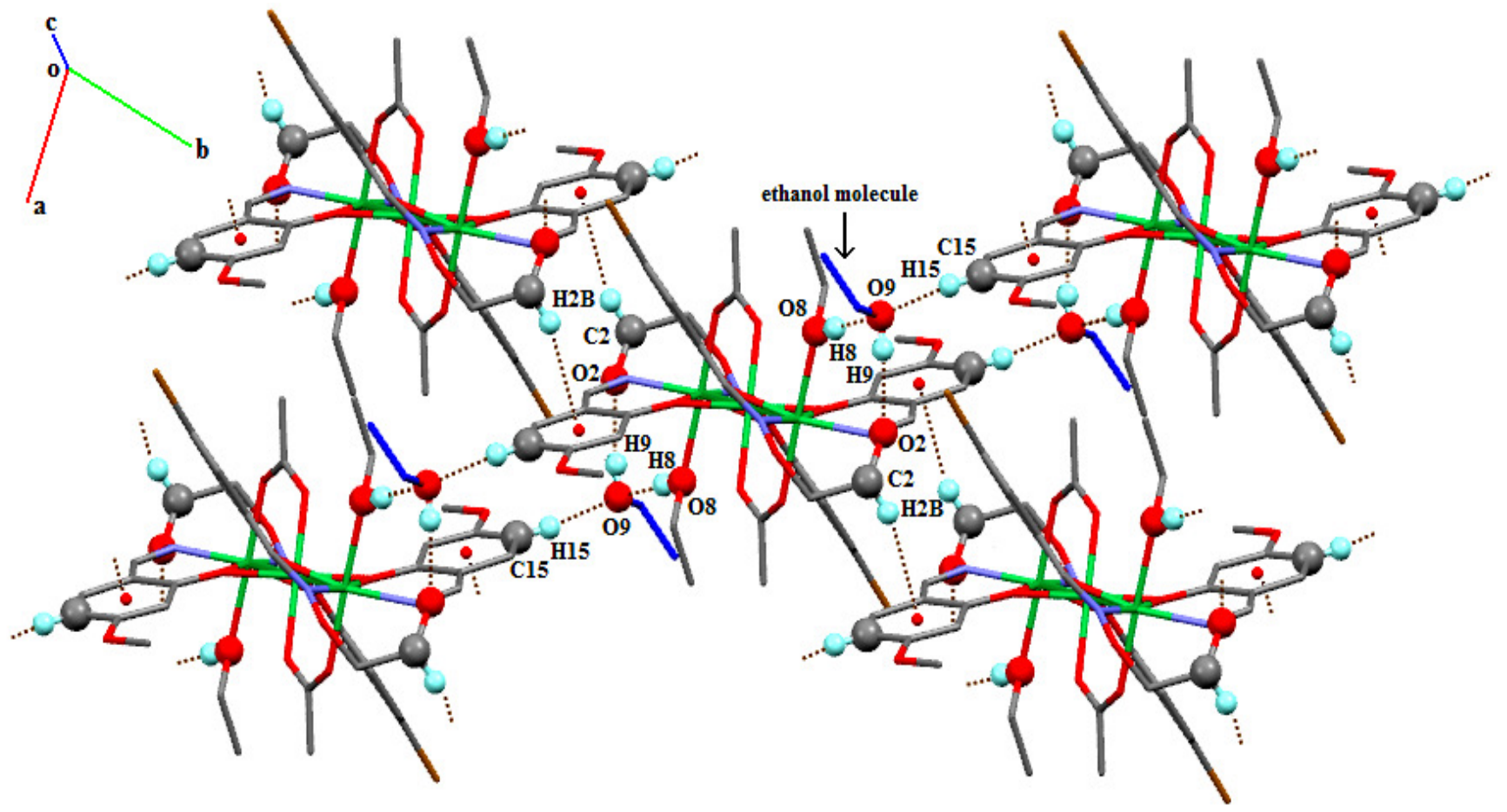

Fig. 5. (color online). View of the 2D layer motif (hydrogen atoms, except those forming hydrogen bonds, are omitted for clarity)

to the oxime oxygen $(\mathrm{O} 2)$ atom of the $\mathrm{L}^{2-}$ unit. Thus, the complex and the non-coordinating ethanol molecules are linked by intermolecular $\mathrm{O} 8-\mathrm{H} 8 \cdots \mathrm{O} 9, \mathrm{O} 9-\mathrm{H} 9 \cdots \mathrm{O} 2$ and $\mathrm{C} 15-$ H15 ... O9 hydrogen bonds into an infinite 1D chain along the [110] crystallographic axis (Fig. 3). Synchronously, this linkage is further stabilized by two pairs of intermolecular C2$\mathrm{H} 2 \mathrm{~B} \cdots \pi_{\text {centroid(C11-C16) }}$ hydrogen bonding interactions between the methylene (-C2H2B) unit of the O-alkyl chain and the benzene ring (C11-C16) of the coordinated $\mathrm{L}^{2-}$ unit to form the other 1D infinite chain along the b-axis, as illustrated in Fig. 4.

Thus, the Ni(II) complex and crystallizing disordered ethanol molecule are linked to form an infinite 2D layer supramolecular structure (Fig. 5) through intermolecular O-H $\cdots \mathrm{O}$, $\mathrm{C}-\mathrm{H} \cdots \mathrm{O}$ and $\mathrm{C}-\mathrm{H} \cdots \pi$ hydrogen bond interactions.

\section{ACKNOWLEDGEMENTS}

This work was supported by the Foundation of Preparative Research of Jin-Chuan Corporation (No. 209125-1102, 1103), the Fundamental Research Funds for the Gansu Province Universities (212086) and the science and technology support funds of Lanzhou Jiaotong University (ZC2012003), which are gratefully acknowledged.

\section{REFERENCES}

1. D. Braga, L. Maini, M. Polito, E. Tagliavini and F. Grepioni, Coord. Chem. Rev., 246, 53 (2003).

2. S.M. Saylor, R.M. Supkowski and R.L. LaDuca, Inorg. Chim. Acta, 361, 317 (2008). 
3. H.Y. Han, Y.L. Song, H.W. Hou, Y.T. Fan and Y.J. Zhu, J. Chem. Soc., Dalton Trans., 1972 (2006).

4. M.E. Braun, C.D. Steffek, J. Kim, P.G. Rasmussen and O.M. Yaghi, Chem. Commun., 24, 2532 (2001).

5. N.L. Rosi, M. Eddaoudi, J. Kim, M. O'Keeffe and O.M. Yaghi, Cryst. Eng. Comm, 4, 401 (2002).

6. M. Eddaoudi, D.B. Moler, H. Li, B. Chen, T.M. Reineke, M. O'Keeffe and O.M. Yaghi, Acc. Chem. Res., 34, 319 (2001).

7. H. Miyasaka, N. Matsumoto, H. Okawa, N. Re, E. Gallo and C. Floriani, J. Am. Chem. Soc., 118, 981 (1996).

8. E. Bayol, T. Gurten, A.A. Gurtena and M. Erbil, Mater. Chem. Phys., 112, 624 (2008).

9. T. Gao, P.F. Yan, G.M. Li, G.F. Hou and J.S. Gao, Inorg. Chim. Acta, 361, 2051 (2008).

10. P.G. Lacroix, Eur. J. Inorg. Chem., 339 (2001).

11. E. Keskioglu, A.B. Gündüzalp, S. Cete, F. Hamurcu and B. Erk, Spectrochim. Acta A, 70, 634 (2008).

12. T.K. Ronson, H. Adams and M.D. Ward, Inorg. Chim. Acta, 358, 1943 (2005).

13. Y.H. Feng, C. Wang, J.X. Xu, L. Xu, D.Z. Liao, S.P. Yan and Z.H. Jiang, Inorg. Chem. Commun., 11, 549 (2008).

14. Y.H. Feng, C. Wang, G.F. Xu, Y. Ouyang, D.Z. Liao and S.P. Yan, Inorg. Chem. Commun., 11, 341 (2008)

15. A.K. Sharma, F. Lloret and R. Mukherjee, Inorg. Chem., 46, 5128 (2007).
16. P.A. Karplus and M.A. Pearson, Acc. Chem. Res., 30, 330 (1997).

17. H.L. Zhu, L.M. Zheng, J. Zhao, W.M. Bu, W.X. Tang, Transition Met. Chem., 24, 131 (1999).

18. H.L. Zhu, Y.X. Tong, X.M. Chen and C.X. Ren, Transition Met. Chem., 26, 528 (2001).

19. P.J. Marini, K.S. Murray and B.O. West, J. Chem. Soc. Dalton Trans., 143 (1983).

20. L. Gomes, E. Pereira and B. de Castro, J. Chem. Soc. Dalton Trans., 1373 (2000).

21. (a) W.K. Dong, L. Li, C.F. Li, L. Xu and J.G. Duan, Spectrochim. Acta A, 71, 650 (2008); (b) W.K. Dong, J.Y. Shi, L. Xu, J.K. Zhong, J.G. Duan and Y.P. Zhang, Appl. Organometal. Chem., 22, 89 (2008). (c) W.K. Dong, J.G. Duan, Y.H. Guan, J.Y. Shi and C.Y. Zhao, Inorg. Chim. Acta, 362, 1129 (2009); (d) W.K. Dong, S.J. Xing, Y.X. Sun, L. Zhao, L.Q. Chai and X.H. Gao. J. Coord. Chem., 65, 1212 (2012); (e) W.K. Dong, Y.X. Sun, Y.P. Zhang, L. Li, X.N. He and X.L. Tang, Inorg. Chim. Acta, 362, 117 (2009); (f) W.K. Dong, Y.X. Sun, C.Y. Zhao, X.Y. Dong and L. Xu, Polyhedron, 29, 2087 (2010); (g) W.K. Dong, X.N. He, H.B. Yan, Z.W. Lv, X. Chen, C.Y. Zhao and X.L. Tang, Polyhedron, 28, 1419 (2009); (h) W.K. Dong, Y.X. Sun, G.H. Liu, L. Li, X.Y. Dong and X.H. Gao, Z. Anorg. Allg. Chem., 638, 1370 (2012).

22. J. Reglinski, S. Morris and D.E. Stevenson, Polyhedron, 21, 2167 (2002). 